\title{
Cell Birth and Death in the Mouse Retinal Ganglion Cell Layer
}

\author{
MOHAMED H. FARAH ${ }^{1 *}$ AND STEPHEN S. EASTER, JR. ${ }^{1,2}$ \\ ${ }^{1}$ Neuroscience Program, University of Michigan, Ann Arbor, Michigan 48109-1048 \\ ${ }^{2}$ Department of Molecular, Cellular, and Developmental Biology, University of Michigan, \\ Ann Arbor, Michigan 48109-1048
}

\begin{abstract}
Here we describe quantitatively the birth and death of the two separate populations of neurons, ganglion cells and displaced amacrine cells, in the mouse retinal ganglion cell layer (GCL). The two cell types, which are roughly equally numerous, were distinguished pre- and postnatally by labeling the ganglion cells retrogradely with fluorescent dye. Embryos were labeled cumulatively with bromodeoxyuridine (BrdU) delivered by an osmotic minipump implanted in the mother; cell birth dates were established as having occurred before or after pump implantation. Early cohorts (GCL cells born before embryonic day [E] 11.8 and E12.8) were $98 \pm 1.1 \%$ and $99 \pm 0.2 \%$ ganglion cells (mean \pm SEM), respectively, and a late cohort (born after E15.8) was $97 \pm 1.2 \%$ displaced amacrines. Thus birth date was a strong predictor of a GCL cell's ultimate identity. Cell death in each cohort was estimated by counting cells at different time points (soon after the cohort was produced and later) and subtracting the later from the earlier number. This method avoids the problem of simultaneous birth and death that has plagued many of the earlier attempts to assess cell death. Negligible numbers died during the first week after a cell's birthday. The amount of cell death differed in the two cohorts; $48.5 \pm 15 \%$ and $29.0 \pm 12.4 \%$ in early and late, respectively, and most of it was postnatal. These findings disagree sharply with an earlier conclusion that ganglion cells die within 5 days of their birthdays or not at all. J. Comp. Neurol. 489:120-134, 2005.

() 2005 Wiley-Liss, Inc.
\end{abstract}

Indexing terms: amacrine; precursor competence, birthdate; fate

A retinal cell's birth date is expected to be influenced by two factors, class and location. We have evaluated these influences by cumulative labeling with bromodeoxyuridine (BrdU; Farah, 2004) to mark cohorts of ganglion cell layer (GCL) neurons born either early or late, and retrogradely labeling the ganglion cells with rhodaminedextran (Fritzsch, 1993; Rachel et al., 2002). Ganglion cells are classified as projection neurons (they send long axons through the optic nerve into the brain) and amacrines as local circuit interneurons (their neurites do not extend very far from the cell body). Elsewhere in the vertebrate central nervous system projection neurons are born before nearby local circuit interneurons (reviewed by Jacobson, 1991); therefore ganglion cells are expected to be born before displaced amacrines. With respect to cell location, GCL cells are born in peripheral retina at ages when none are being produced in the central retina (Dräger, 1985); therefore it seems likely that peripheral ganglion cells will be born after central displaced amacrines. Our results fulfilled both expectations. The early and late cohorts comprised nearly exclusively ganglion cells and displaced amacrine cells, respectively, and the few late cohort ganglion cells were in the peripheral retina. As we discuss below, these results clarify some aspects of the generation of neuronal diversity and the "competence" of progenitor cells (Cepko et al., 1996).

Grant sponsor: National Institutes of Health; Grant number: MH14279 (to M.H.F.); Grant sponsor: the Rackham School of Graduate Studies Merit Fellowship (to M.H.F.); Grant sponsor: the Herman and Margaret Sokol Faculty Award in Sciences (to S.S.E.).

Dr. Mohamed H. Farah's current address is Division of Neuropathology, Johns Hopkins University, 558 Ross Research Bldg., 720 Rutland Ave., Baltimore, MD 21205-2196.

*Correspondence to: Mohamed H. Farah, Division of Neuropathology, Johns Hopkins University, 558 Ross Research Bldg., 720 Rutland Ave., Baltimore, MD 21205-2196. E-mail: mfarah2@jhu.edu

Received 23 December 2004; Revised 26 February 2005; Accepted 22 May 2005

DOI 10.1002/cne.20615

Published online in Wiley InterScience (www.interscience.wiley.com). 
With respect to the extent of cell death, most studies did not differentiate the two classes and assessed cell death in the GCL as a whole. When ganglion cells were specifically examined, estimated loss ranged from 9\% (Young, 1984) to 90\% (Galli-Resta and Ensini, 1996), with most estimates toward the middle of that range, consistent with earlier studies of cell death in projection neurons (reviewed by Jacobson, 1991). Cell death in local circuit interneurons is generally smaller than in projection neurons, ranging from zero (Armstrong and Clarke, 1979; McKay and Oppenheim, 1991; Cook et al., 1998) to 20\% (Alexiades and Cepko, 1997). Much of the variability is probably attributable to differences in methods and assumptions, some of which we discuss later. We have estimated cell death directly by counting the number originally generated and the number remaining later and subtracting the two. Such a direct method cannot usually succeed because cell death begins before all the cells have been born (Williams et al., 1986; Galli-Resta and Ensini, 1996), but we have circumvented this problem by restricting our analysis to cohorts of cells born over a few days during which cell birth and death do not overlap.

As to when cells die, most studies have been noncommittal, but Galli-Resta and Ensini (1996) concluded that rat ganglion cells died only during their first 5 days of life, and if they survived that initial period they did not die thereafter. The suggestion of an early and brief period of vulnerability followed by a late and prolonged period of safety is novel, and we evaluated these ideas directly by assessing early and late cell death in both cohorts. We found the opposite, that is, little or no cell death during the first week following the birthday (a brief period of invulnerability), and abundant cell death thereafter.

\section{MATERIALS AND METHODS BrdU labeling with osmotic minipumps}

Timed-pregnant CD-1 mice from Charles River Laboratories (Wilmington, MA) were used exclusively. E0.0, the onset of embryonic life, was assumed to be 2 AM of the night of coupling. Pregnant dams were implanted subcutaneously with a BrdU-releasing osmotic minipump (model 2001, Alzet Osmotic Pumps, Durect, Palo Alto, CA) at one of three gestational ages: E11.5 $(\mathrm{n}=11)$, or E12.5 $(\mathrm{n}=8)$, or E15.5 $(\mathrm{n}=6)$. The pumps were always implanted between 1:30 and 2:00 PM and thereafter released $1 \mu \mathrm{l} / \mathrm{h}$, or $50 \mu \mathrm{g} / \mathrm{h}$ of BrdU, for 7 days, a total of $8,400 \mu \mathrm{g}$. All proliferating retinal cells were labeled, and the amount of apoptosis was indistinguishable from normal (Farah, 2004); this same reference provides further details of pump preparation, implantation, and validation. All animal protocols were approved by the University of Michigan Committee on the Use and Care of Animals.

\section{Tissue preparation}

Mice were briefly anesthetized with carbon dioxide and then sacrificed by cervical dislocation. Tissues were immersion-fixed in freshly made $4 \%$ paraformaldehyde/ $0.1 \mathrm{M}$ phosphate buffer (PB), pH 7.4, for 6-8 hours or overnight at room temperature (RT). Embryos E13.5 and younger were fixed intact; older embryos and neonates were decapitated, and their heads were fixed; and the eyes of P30 mice were dissected out and fixed in isolation. Tissues were stored in fixative at $4^{\circ} \mathrm{C}$.
Embedding and freezing protocols were adapted from $\mathrm{Hu}$ and Easter (1999). Three PB washes of 10-15 minutes each were followed by $2-3$ hours in $5 \%$ sucrose/PB at RT and $4-5$ hours in $15 \%$ sucrose/PB at RT. Then the tissue was embedded in $15 \%$ sucrose $/ 7.5 \%$ gelatin/PB overnight at $37-42^{\circ} \mathrm{C}$. The samples were quick-frozen in dry ice/2methylbutane, frozen-sectioned at $10 \mu \mathrm{m}$, and mounted on subbed slides. They were then air-dried at RT for 3-4 hours and either processed immediately or stored at $-20^{\circ} \mathrm{C}$ for later processing.

\section{Identification of ganglion and displaced amacrines cells}

Ganglion cells were identified by retrograde labeling from their axons with rhodamine-dextran, by using the methods of Fritzsch (1993), Von Bohlen und Halbach (1999), and Rachel et al. (2002), with slight modifications. Small fragments of Gelfoam (Pharmacia, Peapack, NJ) were loaded with fixable rhodamine-dextran, 3,000 molecular weight (C/N D3308, Molecular Probes, Eugene, OR) and allowed to dry. Embryonic eyes were dissected from live embryos in artificial cerebrospinal fluid (ACSF; recipe in Von Bohlen und Halbach, 1999) at RT. The optic stalk was cut close to the eye, and within a minute, a Gelfoam fragment was placed on the cut optic stalk for 4-5 minutes, after which the eye was washed with ACSF and incubated in aerated ACSF for 2 hours at RT. The eyes were then fixed in freshly made $4 \%$ paraformaldehyde in 0.1 M PB, embedded, frozen-sectioned, and processed for BrdU immunocytochemistry as described below. We attempted to identify more definitively the rhodaminenegative cells by staining with antibodies against markers for displaced amacrines (choline acetyl transferase: Hayden et al., 1980; syntaxin: Marquardt et al., 2001), but we were unsuccessful, probably because of the denaturing conditions required for BrdU staining. Operationally, rhodamine-positive cells in the GCL were classed as ganglion cells, and rhodamine-negative cells in the GCL with large nuclei were classed as displaced amacrines. Cells in the GCL with small nuclei were assumed to be glial and were not counted. The displaced ganglion cells, with cell bodies in the inner plexiform or inner nuclear layers, were recognized (see Fig. 4), but they were not counted because their numbers were insignificant.

In postnatal retinas the retrograde labeling was slightly modified. First, 3\% lysolecithin (Sigma, St. Louis, MO) dissolved in water was mixed with fragments of rhodamine-dextran to enhance the uptake of the tracer (Frank et al., 1980). Second, a drop of $1 \%$ agarose was placed on top of the Gelfoam fragment to confine the rhodamine-dextran to the cut site of the optic nerve. Third, labeled retinas were incubated for 18 hours in aerated ACSF. The longer incubation was necessary to label ganglion cells at the retinal periphery.

\section{Section staining}

Nonspecific antibody binding was blocked by incubation in 5\% goat serum (Jackson ImmunoReseach, West Grove, PA) $/ 0.3 \%$ Triton (Sigma)/PB for 1 hour at RT. Primary antibodies were applied overnight at $4{ }^{\circ} \mathrm{C}$ in a humidified chamber, washed in PB (four times, 15-20 minutes each), and the secondary antibodies were applied for 3-4 hours at RT in the dark. The sections were further washed, counterstained, mounted (ProLong Antifade Kit, Molecular Probes), and coverslipped. 
For BrdU immunocytochemistry, sections were denatured in $2 \mathrm{~N} \mathrm{HCl} / \mathrm{PB}$ for 30 minutes at RT, washed for 5-10 minutes in $0.1 \mathrm{M}$ sodium borate buffer, $\mathrm{pH} 8.5$, and washed twice more in PB. BrdU was detected with 1:200 rat anti-BrdU (Serotec, Raleigh, NC), visualized with 1:100 fluorescein isothiocyanate (FITC)-conjugated goat anti-rat (Jackson ImmunoResearch). Differentiated neurons were identified by 1:100 rabbit anti- $\beta$-tubulin type III (a gift from Dr. Anthony Frankfurter, University of Virginia) and visualized with 1:500 Alexa Fluor 546 goat anti-rabbit (Molecular Probes). Nuclei were stained with $0.5 \mu \mathrm{g} / \mathrm{ml}$ DAPI (fluoresces blue) or $20 \mathrm{ng} / \mathrm{ml}$ propidium iodide (PI; fluoresces red; Molecular Probes).

Some retinas were double labeled for BrdU and terminal deoxynucleotidyl transferase-mediated biotinylated UTP nick-end labeling (TUNEL; Intergen, Purchase, NY). TUNEL-positive cells fluoresced green; therefore BrdU was visualized by a red secondary antibody, 1:500 Alexa Fluor 555 goat anti-rat (Molecular Probes). Nuclei were counterstained with DAPI.

The quantitative data were obtained with a standard fluorescence microscope (Leica Aristoplan) through a $50 \times$ water objective. All of the photomicrographs reproduced here were acquired by laser scanning confocal microscopy (model LSM 510, Carl Zeiss).

\section{Nuclear counting}

Nuclear profiles in the GCL were counted in retinal sections cut transversely through the head. Every 5th (for E12.5) or 10th (for E15.5 and older) section was examined, and the total number of nuclear profiles in the GCL was counted in each. The reliability of this sampling schedule was tested on E12.5 retinas by counting BrdU-negative nuclei (the early cohort; see below) in two independent sets of sections of the same retina (e.g., sections $1,6,11$, 16. . .to produce one estimate and sections $2,7,12,17$. . to produce a second estimate). Two retinas were evaluated this way, and the two estimates differed by only $4.5 \%$ in one retina and $5.2 \%$ in the other, which we judge to be an acceptable level of reliability.

The total number of cells per cohort was estimated with the modified Abercrombie correction (Abercrombie, 1946; Konigsmark, 1970). This measure uses the diameters of nuclear profiles as raw data and requires knowing both the average diameter and the diameter of the smallest visible profile. These numbers were determined separately for each age. The average nuclear diameter was obtained from sagittal sections, which provide a view perpendicular to the transverse sections from which nuclear counts were obtained; 200 were measured. The smallest visible nuclear profile was obtained by measuring the diameters of 50 small nuclear profiles, and the smallest value was used in the calculation. All measurements of nuclear diameter were made in images acquired by Image 1 (Universal Imaging, West Chester, PA), calibrated against a stage micrometer (Edmund Scientific, Barrington, $\mathrm{NJ}$ ).

\section{RESULTS The early cohorts}

To identify a population of cells born early, single osmotic pumps containing BrdU were implanted into pregnant dams early in gestation, at E11.5. (The first GCL neurons are born after E10.0; Sidman, 1961; Farah, 2004.) The pumps delivered BrdU for 7 days, intranuclear BrdU incorporation reached a detectable level in a few cells by about 4-7 hours post implantation (E11.8), and all cycling nuclei were labeled by about 19 hours post implantation (Farah, 2004). Therefore an implantation at E11.5 labeled all cycling nuclei at least until E18.5, and retinas examined between 19 hours and 7 days post implantation contained a population of BrdU-negative nuclei all of which had completed their terminal S-phase before about E11.8. This is the E11.8 cohort. We also implanted at E12.5, which produced an E12.8 cohort (see below).

Cellular identities assessed early in development. Three dams were implanted with BrdU pumps at E11.5 and sacrificed at E12.5, E15.5, and E18.5; then two retinas from each of the three litters were stained with antibodies against BrdU and neuron-specific $\beta$-tubulin type III (Easter et al., 1993). At E12.5 (Fig. 1A,B), the retina had three distinct layers: the optic fiber layer (innermost, no nuclei, $\beta$-tubulin-positive cytoplasm), a thin neural layer (NL: intermediate, nuclei mostly BrdU-negative, cytoplasm $\beta$-tubulin-positive), and a much thicker neuroblastic layer (NBL: outermost, nuclei mostly BrdU-positive, cytoplasm mostly $\beta$-tubulin-negative). The BrdU-negative nuclei in the NL were all $\beta$-tubulin-positive and therefore neurons. The few $\beta$-tubulin-positive cells in the NL that were also BrdU-positive were neurons that completed their terminal S-phase after E11.8. BrdU-negative/ $\beta$-tubulin-positive cells in the NBL were also early-born neurons and probably included some that were migrating to the NL (Lee et al., 2003) and others that were destined to remain in the outer retina (Sidman, 1961; Carter-Dawson and LaVail, 1979; Schnitzer and Rusoff, 1984; Rich et al., 1997; Rapaport et al., 2004). Because they were so sparse, no more than a few percent of the NL neurons, we did not count them; hereafter the E11.8 cohort is restricted to cells in the NL.

At E15.5 (Fig. 1C,D), the retinal layering was similar to that at E12.5, but all layers were thicker. In the NL, all cells remained $\beta$-tubulin-positive, but in contrast to E12.5, the BrdU-positive nuclei outnumbered the BrdU-negative

Fig. 1. The early cohort in prenatal retina. Pumps were implanted in pregnant dams on E11.5. Dams were sacrificed on E12.5 (A,B, adjacent sections), E15.5 (C,D, adjacent sections), and E18.5 (E,F, nonadjacent sections). The retinas were stained for either BrdU and $\mathrm{PI}(\mathrm{A}, \mathrm{C}, \mathrm{E})$ or BrdU and $\beta$-tubulin $(\mathrm{B}, \mathrm{D}, \mathrm{F})$. BrdU is green, and $\beta$-tubulin and PI are red. The inner limiting membrane is down, and the pigmented epithelium is up. The vertical bars on the right indicate the neural layer (NL) and the neuroblastic layer (NBL). A: On E12.5, the nuclei of the early cohort (red: PI-positive/BrdU-negative) occupied a thin layer on the inner retinal surface. Those nuclei born later (yellow: PI-positive/BrdU-positive) were segregated to the outer retina. B: The birthdate-related stratification in A correlated with neural phenotype. The thin NL was defined by $\beta$-tubulin-positive cells, most of them with unstained nuclei (BrdU-negative) and processes (the optic fiber layer [OFL]). The thicker NBL comprised mostly nonneurons ( $\beta$-tubulin-negative), most of which were BrdU-positive. Exceptions were rare: neurons in the NBL (horizontal arrow) and lateborn neurons in the NL (vertical arrow). C: On E15.5 the NL included more BrdU-positive nuclei (yellow) than at E12.5. D: BrdU-positive (arrowhead) and -negative (arrow) nuclei were intermixed in the NL. E: On E18.5, the ganglion cell layer (GCL) was distinct, separated by the inner plexiform layer (IPL) from the rest of the NL and the NBL. F: BrdU-positive nuclei (arrowhead) outnumbered the BrdU-negative ones (arrow) in the GCL. Scale bars $=20 \mu \mathrm{m}$. 

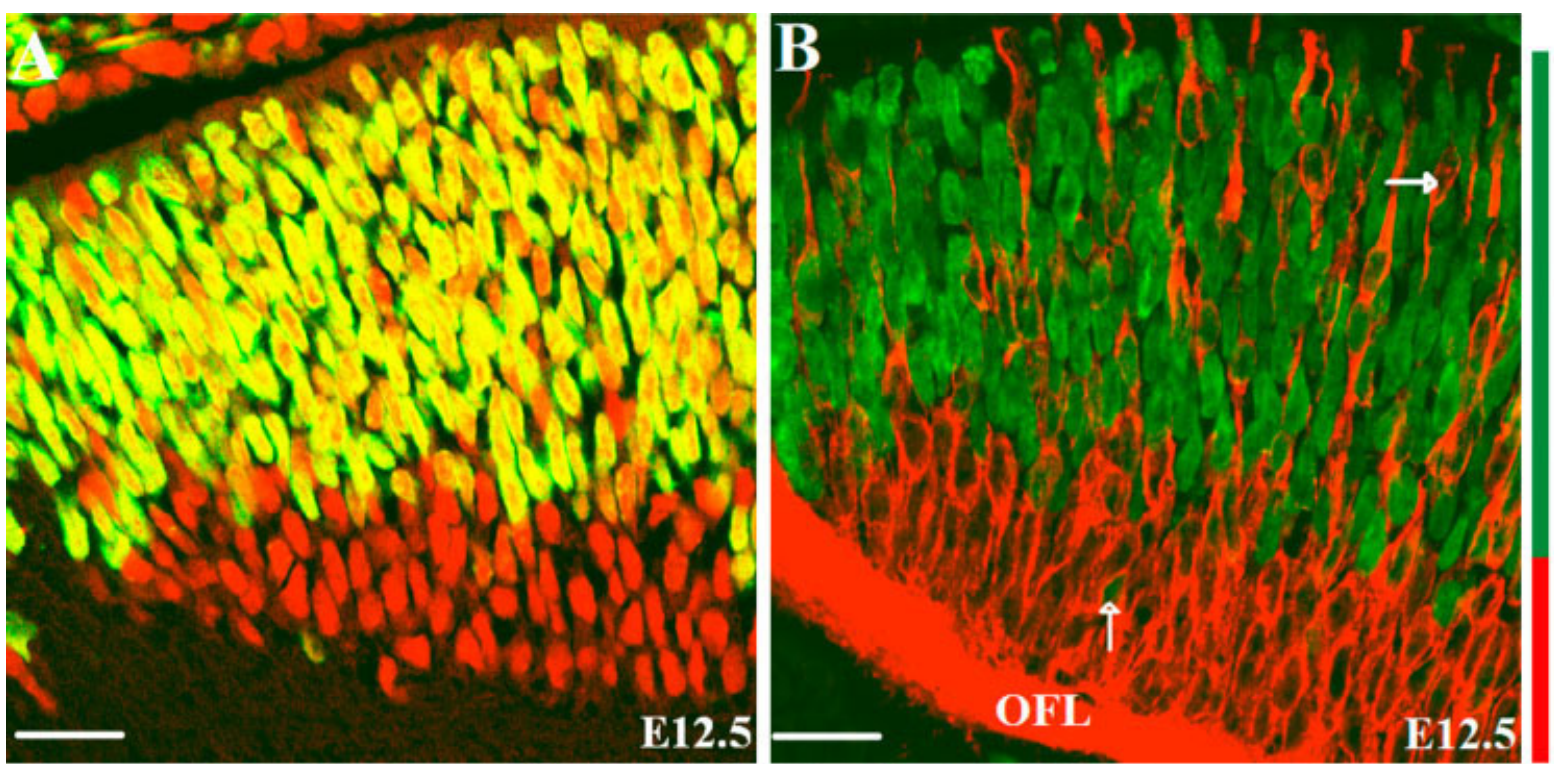

NBL
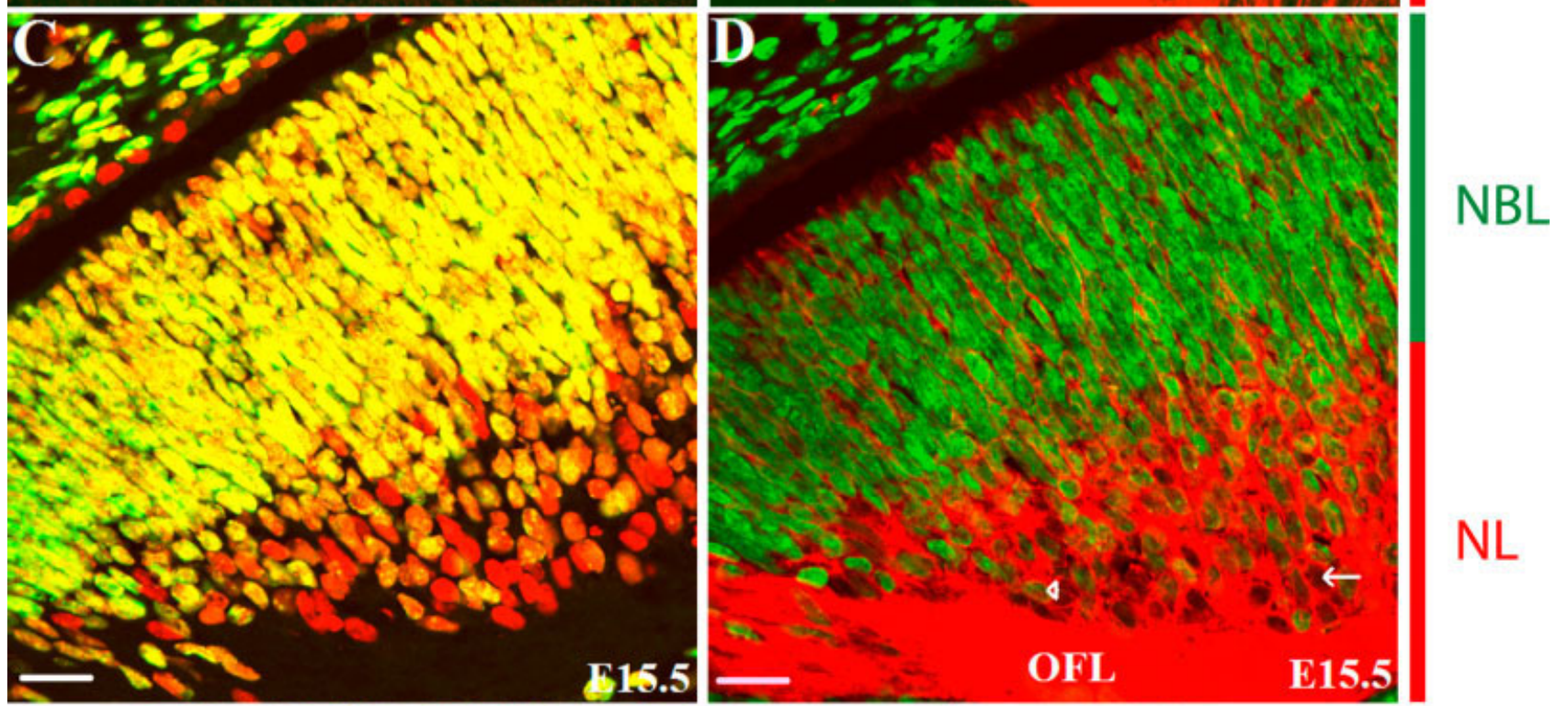

Wh

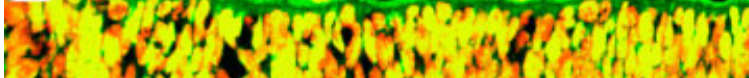

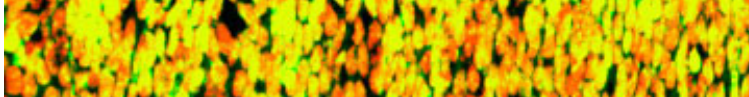

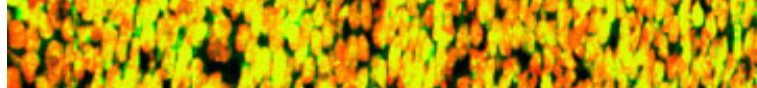

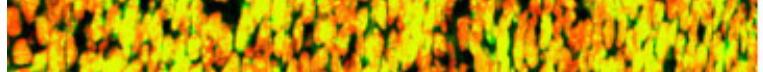

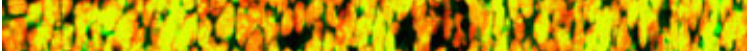

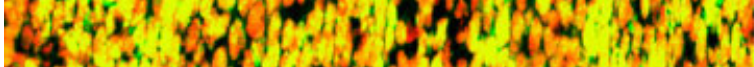

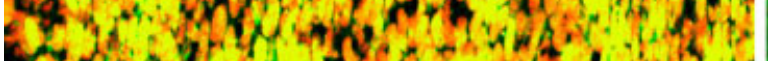

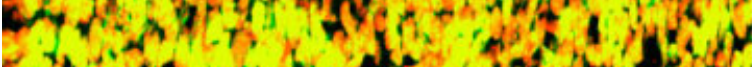

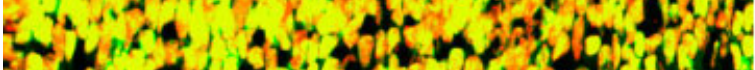

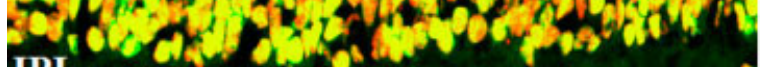

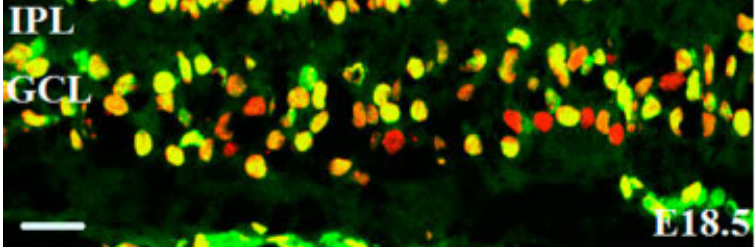

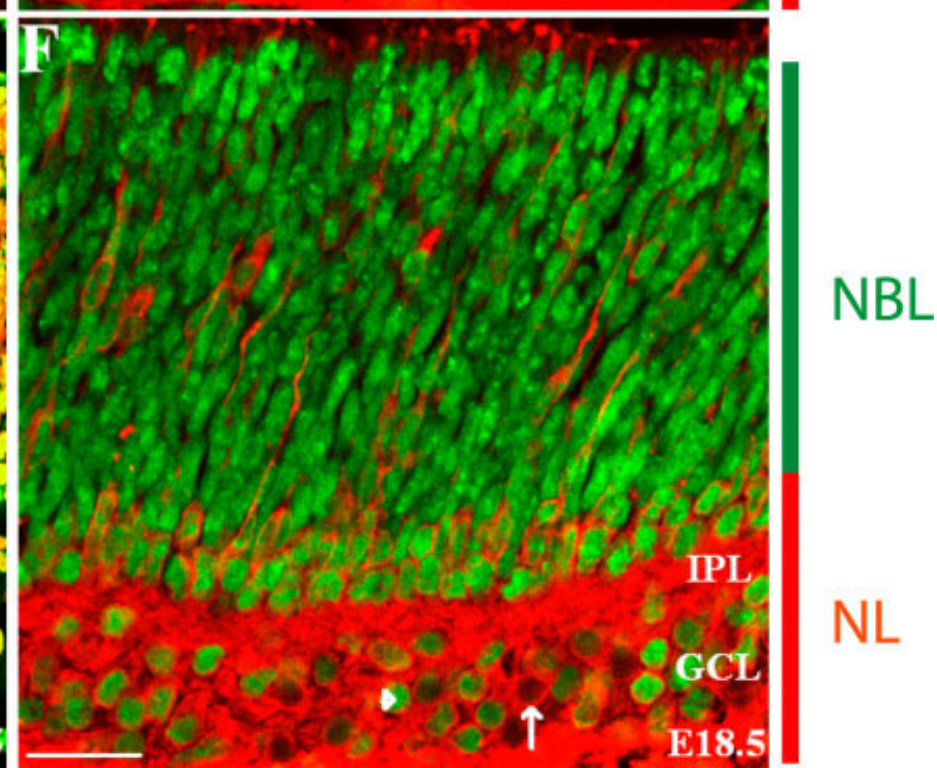


ones, indicating that GCL neurogenesis had continued during the intervening 3 days. BrdU-positive and -negative nuclei were thoroughly intermingled in the NL, indicating that new neurons were added interstitially, rather than at the retinal margin as occurs in fishes and frogs (Hollyfield, 1972; Straznicky and Gaze, 1971). The NBL still contained a few $\beta$-tubulin-positive/BrdUnegative cells, probably many of the same ones that were embedded among the neuroepithelial cells at E12.5. At E18.5 (Fig. 1E,F), the inner plexiform layer divided the NL into the GCL and the nascent inner nuclear layer (INL), but the boundary between the INL and the NBL was indistinct. BrdU-positive and -negative nuclei remained intermingled in the GCL both centrally (Fig. 1E) and peripherally (not shown). The NBL still contained a few $\beta$-tubulin-positive/BrdU-negative cells. We conclude that the cells of the E11.8 cohort were exclusively neurons, and the vast majority of the retinal neurons born before E11.8 were destined for the GCL.

The presence of ganglion cells in the E11.8 cohort was established by retrograde labeling with rhodaminedextran. Two dams were implanted with BrdU-containing pumps at E11.5, and embryos were obtained at E12.5 $(\mathrm{n}=$ $4)$ and E13.5 $(n=8)$. Only a few retinal cells were backfilled at E12.5 (data not shown), probably because most presumptive ganglion cells had not yet sent axons to the label site by that time. At E13.5 rhodamine was concentrated in the optic nerve, the optic fiber layer, and the NL (Fig. 2A,C), indicating that the label reached the neural retina through retrograde axonal transport rather than diffusion through extracellular space. The rhodaminepositive layer was thinner than the $\beta$-tubulin-positive layer (compare the red areas of Fig. 2A and B), consistent with the earlier conclusion that some of the early neurons in the NBL were destined for outer retinal layers. BrdUpositive nuclei could be discerned in the rhodamine-filled cells as central yellow ovals, but BrdU-negative nuclei were masked by the rhodamine and therefore invisible (Fig. 2C,D). These images show that the ganglion cells were a major part of the E11.8 cohort.

To obtain an estimate of their numbers, we counted BrdU-negative/rhodamine-positive cells in sections counterstained with DAPI, a general nuclear stain. Our confocal microscope had only two channels, red and green (Fig. 2A-D), which were inadequate to visualize DAPI-stained nuclei, therefore the scoring was carried out on a standard fluorescence microscope with three channels. Individual nuclei were first located in the blue channel (all nuclei), then viewed in the green channel (BrdU), and finally the red channel (rhodamine). Of the eight E13.5 retinas backfilled with rhodamine-dextran, the three best labeled were analyzed quantitatively with the modified Abercrombie correction to determine the percentage of BrdU-negative cells that were also rhodamine-positive. The grand mean $( \pm$ SEM) was $98 \pm 1.1 \%$ (Fig. $2 \mathrm{E}$ ). The remaining $2 \%$ may have been displaced amacrine cells or ganglion cells that failed to fill. Thus, the E11.8 cohort comprised predominantly ganglion cells.

Prenatal cell death. The number of cells in the E11.8 cohort was counted in embryos of various ages to obtain an estimate of losses through cell death. Ten dams were implanted with BrdU-containing pumps at E11.5 and sacrificed at E12.5 $(\mathrm{n}=4), \mathrm{E} 15.5(\mathrm{n}=3)$, and E18.5 $(\mathrm{n}=3)$. BrdU-negative nuclei in the NL were counted in six retinas from each dam (Fig. 3A-C). The value obtained at
E12.5 was taken as the initial value of the early cohort against which the later values were compared. This approach requires that cell death in the early cohort did not begin until cell birth had finished; an earlier study established this to be the case. Farah (2004) examined cell death by using the TUNEL reaction and found that sections of E12.5 retinas contained several thousand cells per section, but only two to three were TUNEL-positive, and nearly all of these were in the NBL. Therefore cell death among neurons in the NL was negligible and possibly absent during the first day after the E11.8 cohort was produced

The grand mean of BrdU-negative nuclei at E12.5 $(3,589 \pm 448)$ was $16 \%$ higher than that at E15.5 $(3,010 \pm$ $156)$ and $9 \%$ higher than that at E18.5 (3,280 \pm 103$)$, but Student's $t$-test found that these small differences were associated with large $P$-values $(P=0.32$ and $P=0.57$ : Fig. 3D) and were therefore not statistically significant. We conclude that prenatal cell death in the early cohort was small and perhaps absent entirely. We considered examining more litters to establish whether the small differences that we observed might be shown to be statistically significant, but a "power test" of our E12.5 data showed that 126 embryos ( 6 from each of 21 dams) would have to be counted to detect a real loss of $10 \%$ (Dr. Julie Horrocks, personal communication). We did not pursue that option, inasmuch as the main aim of this part of the work was to test directly the conclusion of Galli-Resta and Ensini (1996) that $90 \%$ of ganglion cells died within the first 5 days following cell birth. The small differences that we saw are not in accord with that conclusion.

Cellular identities assessed after developmental cell death. BrdU-containing minipumps were implanted at E12.5, thereby producing a population of unlabeled cells, the E12.8 cohort. This change in the age at implantation was prompted by the need to avoid BrdU-negative GCL cells born after implantation. Such false positives would

Fig. 2. Initial (prenatal) cellular identities in the early cohort. A pump was implanted in a pregnant dam on E11.5, and the dam was sacrificed on E13.5. The embryonic retinas were labeled retrogradely with rhodamine-dextran, sectioned, and either reacted for BrdU (green) and/or stained with DAPI (blue, not shown), or stained for $\beta$-tubulin (red). A: Retinal section through the origin of the optic nerve (arrow) reacted for BrdU. Rhodamine-positive cells and processes in the retina are ganglion cells and axons, respectively. A few cells outside the retina (e.g., arrowhead) also picked up rhodamine. The boxed area is shown in C. B: A similar section through a control retina (no rhodamine-dextran application) stained for $\beta$-tubulin alone. C: Higher magnification of the boxed area in A. The BrdU-positive nuclei were yellow (arrowhead: green BrdU and red rhodamine). The BrdU-negative nuclei, which were visible as unstained ovals in Figure 1 , are invisible here because the rhodamine extended through the nucleus. The arrow points to a cell that was shown in DAPI staining (see text) to include a BrdU-negative nucleus. D: Retinal section with rhodamine alone. Ganglion cell bodies lay closer to the inner limiting membrane (ILM) than to the outer limiting membrane (OLM), and a few (e.g., asterisk) had apical processes extending to the OLM. E: Quantitative analysis of the cellular identities of the early cohort. Three embryos (E13.5) were used, one retina from each. The black columns indicate the BrdU-negative cells (the early cohort), and the white columns indicate the BrdU-negative/rhodamine-positive cells (members of the early cohort that are ganglion cells). The far right pair of columns shows the two grand means. Ganglion cells constituted $98.0 \pm 1.1 \%$ of the early cohort. Scale bars $=50 \mu \mathrm{m}$ in A,B; 20 $\mu \mathrm{m}$ in $\mathrm{C}, \mathrm{D}$. 

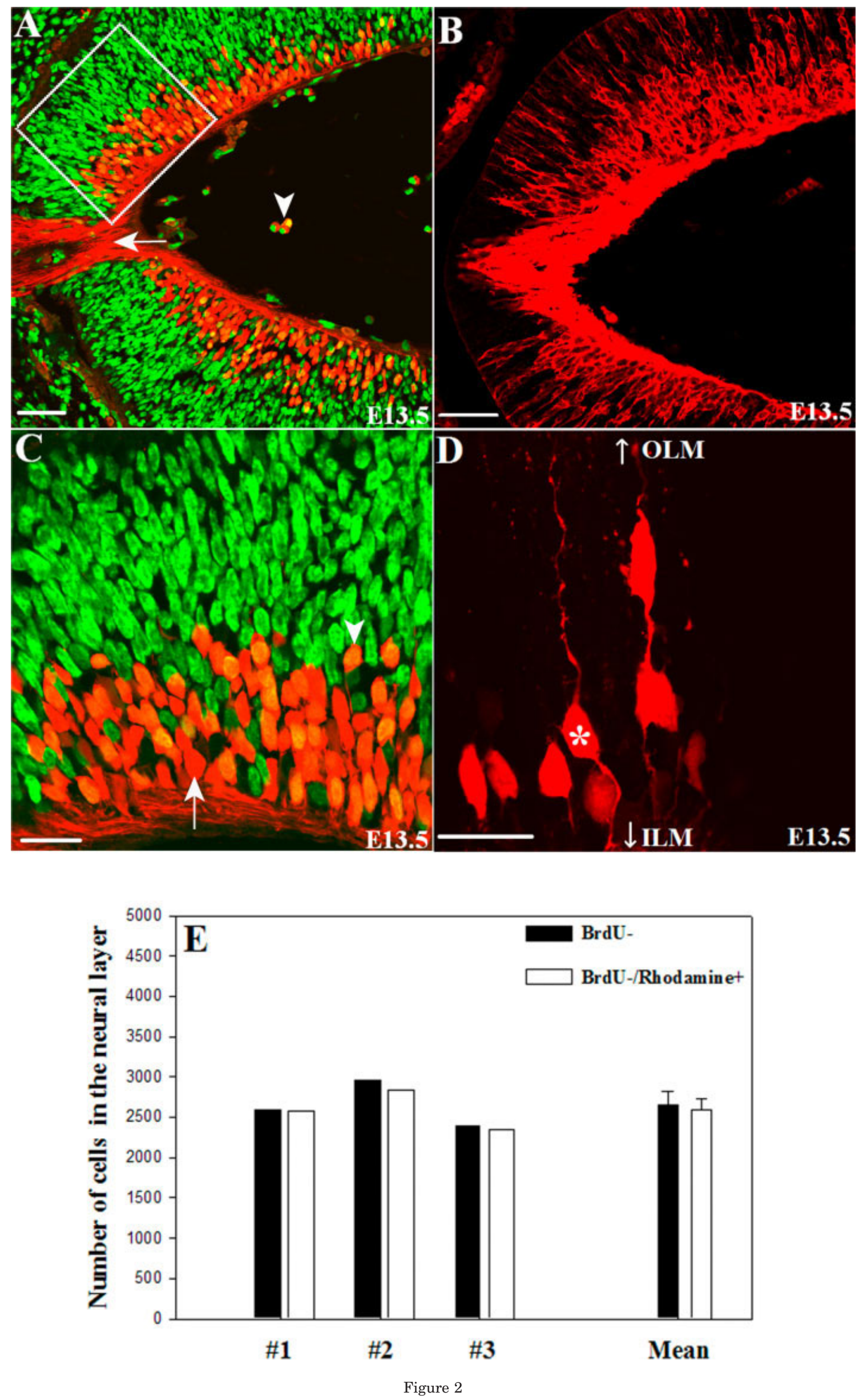


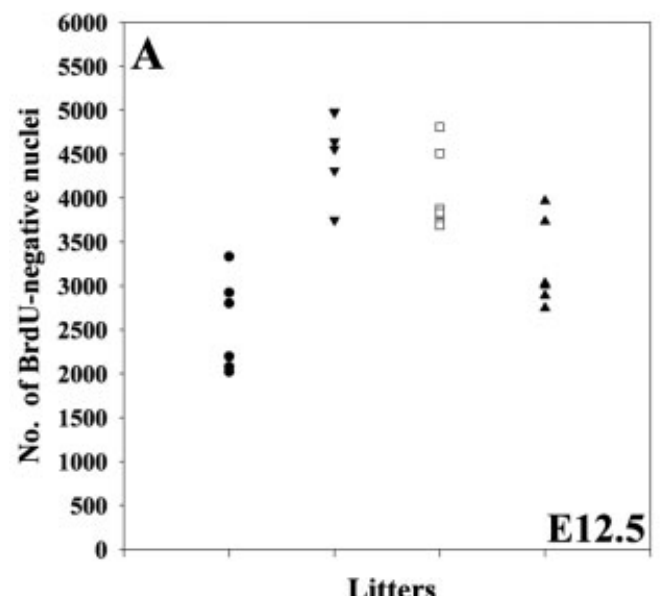

Litters

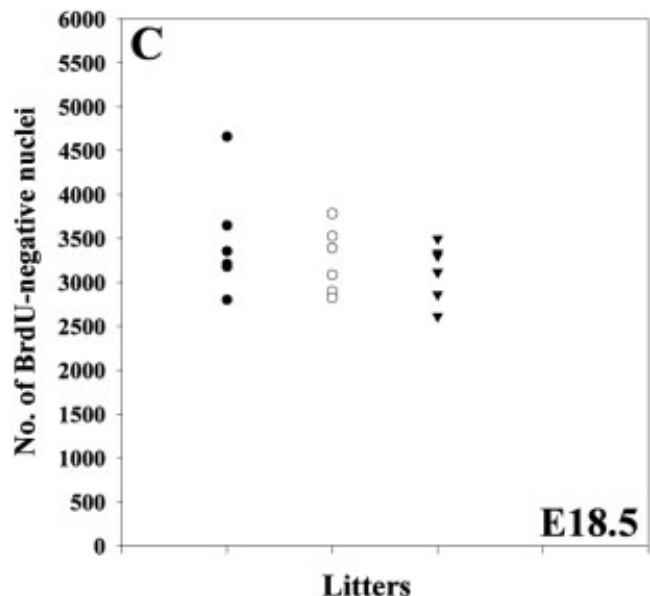

Fig. 3. Prenatal cell death in the early cohort. Pumps were implanted in pregnant dams on E11.5. Dams were sacrificed on E12.5, E15.5, and E18.5. BrdU-negative nuclei were scored in 6 retinas/litter at all ages, and the numbers per retina were calculated by using the modified Abercrombie correction. In $\mathrm{A}-\mathrm{C}$, each point represents one retina from a particular litter, and individual litters are separated

be expected if the supply of BrdU were exhausted before GCL neurogenesis was complete. The pumps deliver for 7 days; therefore a pump implanted at E11.5 would be expected to cease delivery at E18.5, before parturition normally occurs, whereas implantation at E12.5 should deliver BrdU right up to parturition. The production of false positives (BrdU-negative GCL nuclei) postnatally, when the pups are no longer in contact with a supply of BrdU, cannot be excluded with absolute certainty, but postnatal GCL neurogenesis is low (Sidman, 1961; Young, 1985). Moreover, many mitoses of BrdU-positive nuclei that occur when no circulating BrdU is available still produce BrdU-positive progeny (Galli-Resta and Ensini, 1996). Therefore we assume that all BrdU-negative cells in the postnatal GCL are members of the E12.8 cohort.

A second potential technical problem concerned the retrograde labeling method; it apparently worked well in the prenatal retinas, but the adult retinas are considerably larger and the larger transport distances might cause
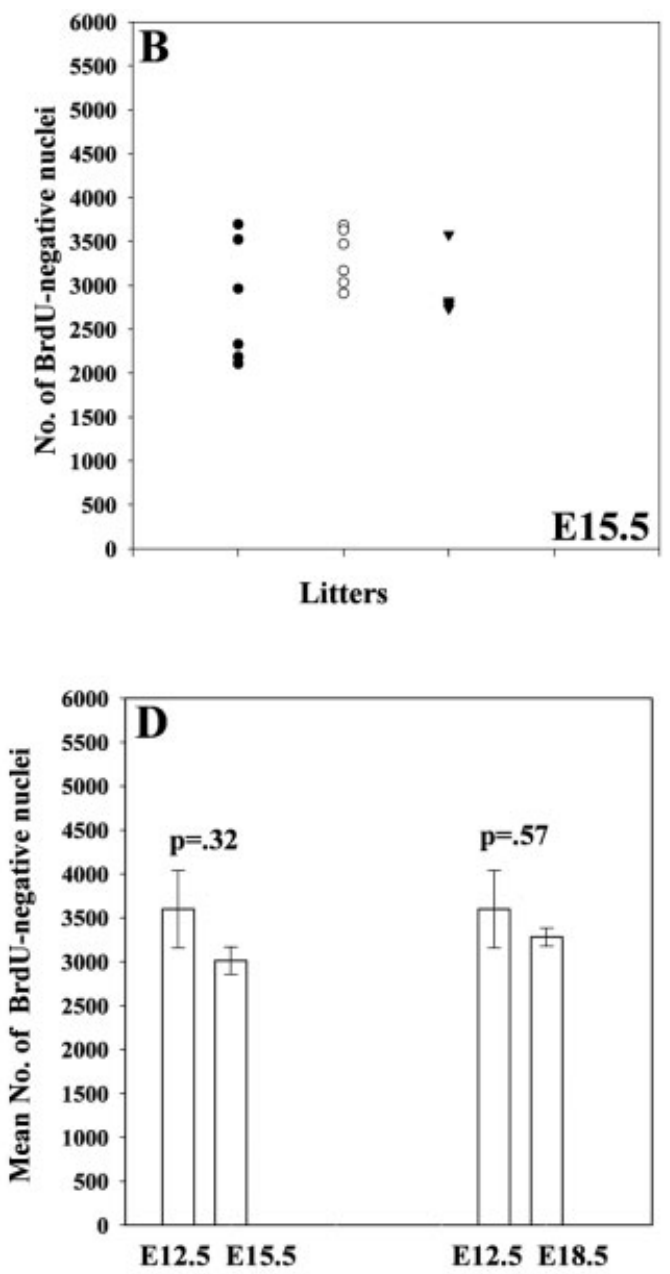

horizontally. A: E12.5. Four litters. Mean \pm SEM $=3,589 \pm 448$. B: E15.5. Three litters. Mean \pm SEM $=3,010 \pm 156$. C: E18.5. Three litters. Mean $\pm \mathrm{SEM}=3,280 \pm 103$. D. The grand means at each age are shown by the columns with the $P$ values for the pairwise comparisons using Student's $t$-test globally.

inadequate labeling. To investigate this, one dam was implanted at E12.5 and allowed to deliver her litter normally. At P30, five of these pups were sacrificed, and all 10 eyes were retrogradely labeled with rhodamine-dextran, sectioned, reacted for BrdU, and counterstained with DAPI. In all of them, rhodamine extended throughout the retina (see Fig. 6A,B) in the appropriate layers (Fig. 4). BrdU-positive and -negative ganglion cell nuclei were interspersed in the GCL along with other BrdU-positive/ rhodamine-negative nuclei. These results indicate that the retrograde labeling worked well in the adult and that such retinas could be analyzed with confidence. Accordingly, cells of the E12.8 cohort (BrdU-negative) were counted in the two best retrogradely labeled retinas, and the percentage of rhodamine-positive cells was calculated. It was similar to the prenatal case: $99 \pm 0.2 \%$ of the BrdU-negative cells were rhodamine-positive and therefore ganglion cells. 

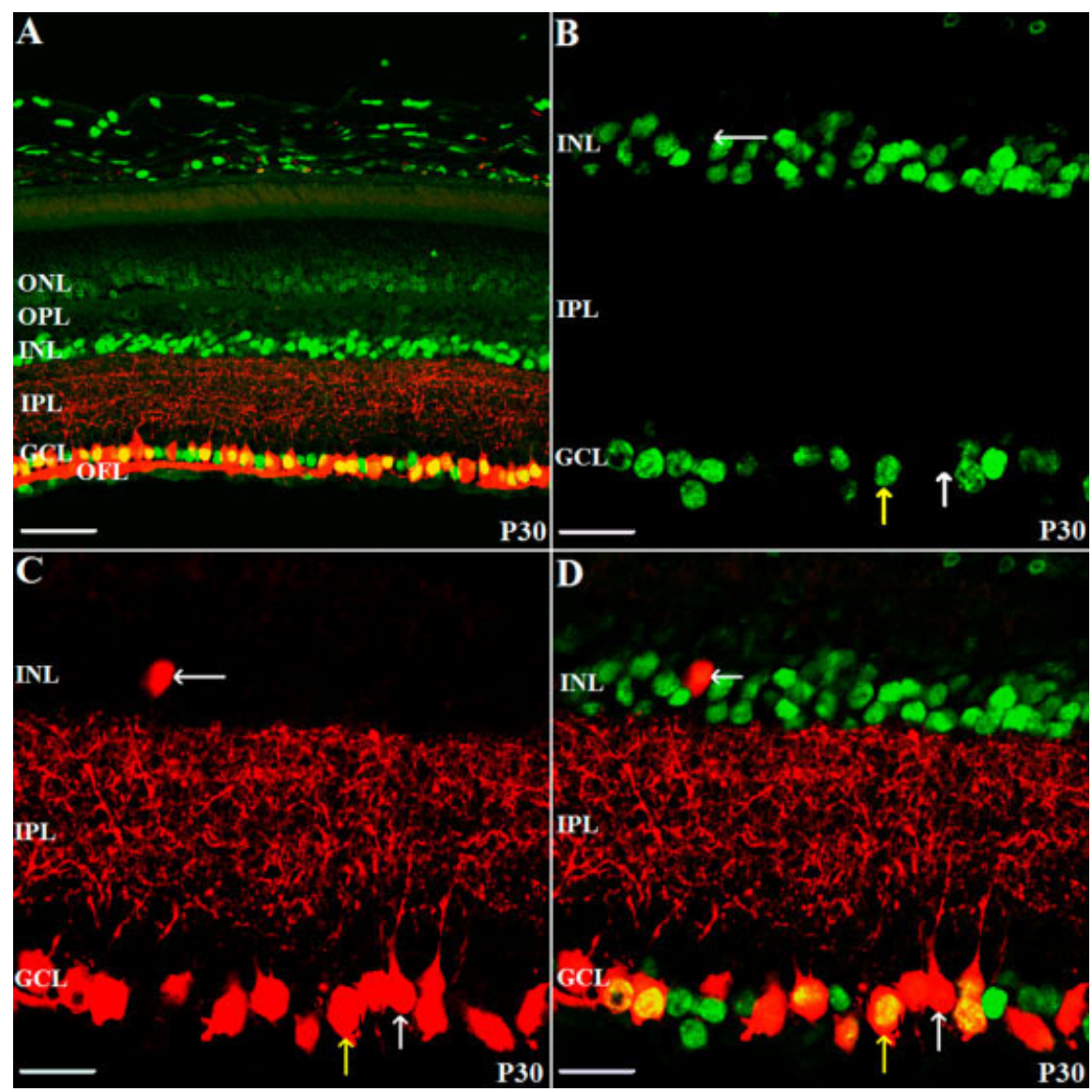

Fig. 4. Final (postnatal) cellular identities in the early cohort. A pump was implanted on E12.5, and a normal delivery followed. At P30, pups were sacrificed, and their retinas were retrogradely labeled with rhodamine-dextran (red), sectioned, and reacted for BrdU (green). A: Central retina. The normal stratification is evident: optic fiber layer (OFL), ganglion cell layer (GCL), inner plexiform layer (IPL), inner nuclear layer (INL), outer plexiform layer (OPL), and outer nuclear layer (ONL). The rhodamine is restricted to the OFL,

Postnatal cell death. Postnatal cell death in the E12.8 cohort was estimated by comparing the numbers of BrdU-negative nuclei in the GCL at P0 and P30 ( $\mathrm{n}=15$ retinas at both ages, 5 pups/litter from three litters, one retina/pup). BrdU-negative nuclei with neuronal characteristics were counted in the GCL, and their numbers in the retina were estimated by using the modified Abercrombie correction. The numbers were 9,793 \pm 679 at $\mathrm{P} 0$ and 5,044 \pm 407 at P30, a cell loss of $48.5 \pm 15 \%$ (Fig. 5A). The two means differed significantly $(P<0.005$, Student's $t$-test).

In summary, 98-99\% of the early cohorts (those cells with terminal S-phase prior to E11.8 or E12.8) were ganglion cells, few and perhaps none died prenatally, and about $48 \%$ died postnatally.

\section{The late cohort}

In the litters of dams implanted at E15.5 the BrdUpositive nuclei were born after about E15.8, and those in the GCL constitute the E15.8 cohort. Note that the early and late cohorts do not constitute the entirety of the GCL;
GCL, and IPL, where axons, somata, and dendrites of eutopic ganglion cells are found. B-D: Three views of the same field of central retina revealing $\mathrm{BrdU}(\mathrm{B})$, rhodamine (C), and both (D). The horizontal and vertical white arrows indicate displaced and eutopic ganglion cells, respectively, both of which are BrdU-negative. The yellow vertical arrow indicates a BrdU-positive eutopic ganglion cell. Scale bars $=100 \mu \mathrm{m}$ in $\mathrm{A} ; 20 \mu \mathrm{m}$ in B-D.

those cells born between E12.8 and E15.8 were not examined directly in this paper.

Cellular identities. P30 eyes $(\mathrm{n}=10$ from five mice whose mother had been implanted at E15.5) were retrogradely labeled with rhodamine-dextran. Numerous rhodamine-positive cells (ganglion cells) lay all over the whole-mounted retina (Fig. 6A-D), but most of them were BrdU-negative. A very few BrdU-positive/rhodaminepositive cells (E15.8 cohort ganglion cells) were concentrated in the far periphery (Fig. 6C), consistent with the center-to-periphery gradient of development (Dräger, 1985). Most BrdU-positive neurons in the GCL were rhodamine-negative and therefore displaced amacrines (Fig. 6C,D).

The fractions of ganglion cells and displaced amacrine cells in this late cohort were determined by scoring all DAPI-positive neurons in sections of the 2 best labeled of the 10 retrogradely labeled retinas. Two attributes were scored: rhodamine positivity/negativity (ganglion cells/ displaced amacrines) and BrdU positivity/negativity (E15.8 cohort/not E15.8 cohort). As Figure 6E illustrates, 

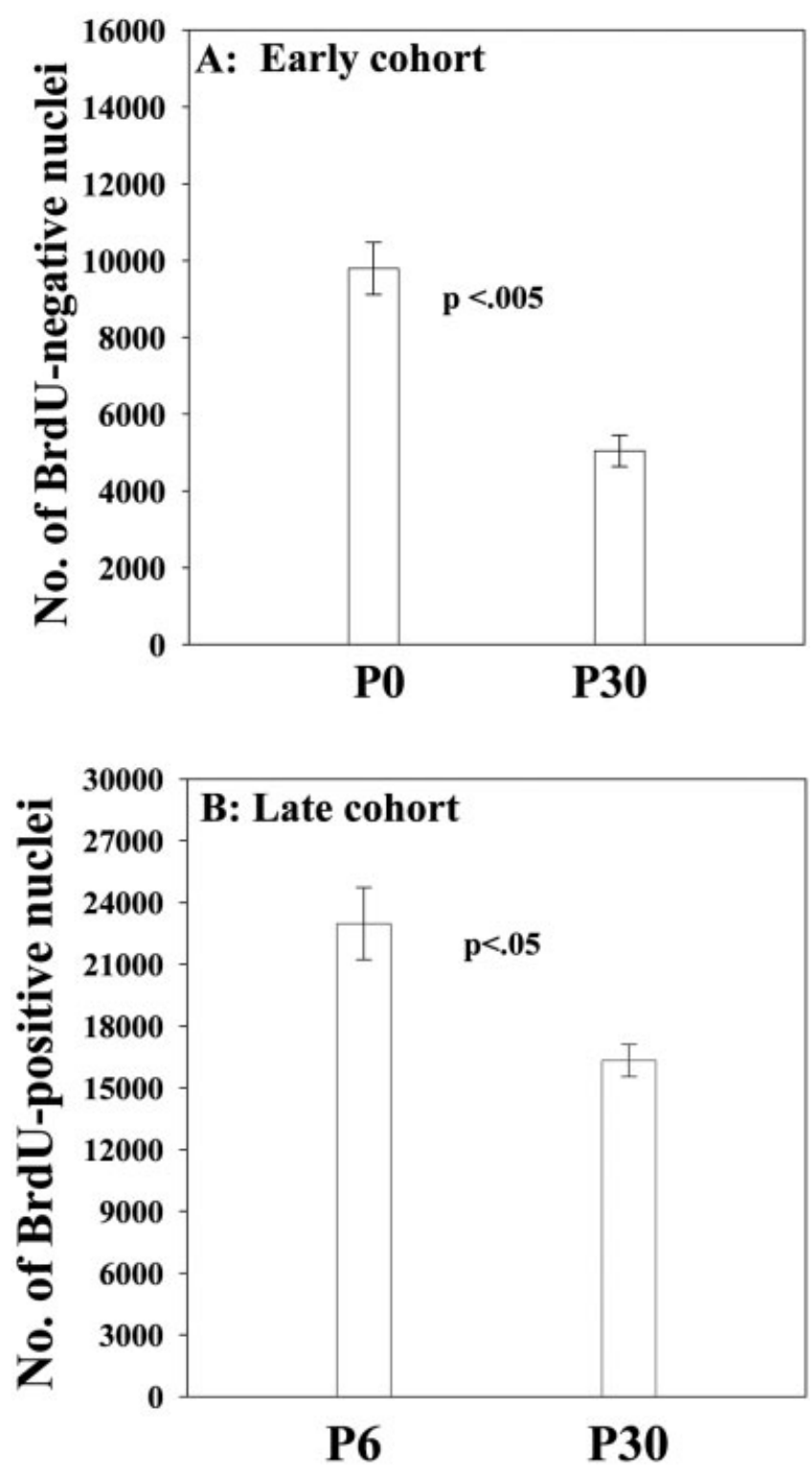

Fig. 5. Postnatal cell death in the early and late cohorts. Pumps were implanted in pregnant dams, which then delivered their litters normally. Eyes from pups were sectioned, reacted for BrdU, and counterstained with DAPI, and the numbers of cells were estimated by using the modified Abercrombie correction. A: Early cohort. The pumps were implanted in three dams at E12.5, five pups from each litter were sacrificed at P0 and P30, and one retina/pup was evaluated. BrdU-negative nuclei were scored, their numbers were estimated, and the grand mean ( \pm SEM) is shown. Cell death was $48.5 \%$ $(P<0.005)$. B: Late cohort. The pumps were implanted in three dams at E15.5, four or five pups from each litter were sacrificed at P6 and P30, and one retina/pup was evaluated. BrdU-positive nuclei were scored, their numbers were estimated, and the grand mean ( \pm SEM) is shown. Cell death was $29.0 \%(P<0.05)$. See text for an explanation of why P6 was the first age evaluated.

the ganglion cells comprised $49 \pm 1.2 \%$ of the total, and the displaced amacrines $51 \pm 1.2 \%$, similar to earlier estimates of the adult mouse GCL (Dräger and Olsen, 1981; Jeon et al., 1998). Of this population, $20 \pm 1.0 \%$ were members of the E15.8 cohort. Figure $6 \mathrm{~F}$ shows that within this cohort, only $3.2 \pm 1.2 \%$ were rhodaminepositive, indicating that $97 \pm 1.2 \%$ of the cells in the E15.8 cohort were displaced amacrines, a complete turnabout from the early cohorts.

Cell death. The estimate of the initial number of cells in the E15.8 cohort was more complicated than that of the earlier cohorts because of different cellular kinetics. Not only is the cell cycle longer at the later date (Alexiades and Cepko, 1996), but the older retina is thicker than the younger. The longer cell cycle imposes a greater delay between S-phase and the onset of migration, and the greater thickness causes a more prolonged migration (Galli-Resta and Ensini, 1996). Moreover, E15.8 cohort cells might be dying as others are produced; therefore the number of cells in the E15.8 cohort was estimated with these complications in mind.

Two dams were implanted at E15.5 and delivered their litters normally. Every day thereafter, one to three pups were sacrificed, and their retinas (one per pup) were sectioned, reacted for BrdU, and counterstained with PI. The nuclei were scored, and the numbers of E15.8 cohort neurons (i.e., BrdU-positive in the GCL) per retina were estimated with the modified Abercrombie correction (Fig. 7A). The number of BrdU-positive cells was low on P0, gradually rose to a peak at $\mathrm{P} 6$ as cells migrated in, and declined thereafter as cells died. The number of BrdU-positive cells present at P6 cannot be assumed to represent the entire initial population of the E15.8 cohort, because if some members of that cohort were dying during the first 6 postnatal days, then the number counted at P6 would underestimate the initial number. It was therefore necessary to assess cell death among the E15.8 cohort during P0-P6.

The time course of cell death was assessed by staining for both BrdU and TUNEL (Fig. 7C). Two pups were sacrificed every day following birth, and every 10th section from two retinas per age was examined thoroughly for cells that were TUNEL-positive/BrdU-positive. TUNELpositive nuclei were present in the GCL from P0 to P6 (Fig. 7B), but no TUNEL-positive/BrdU-positive cell was observed in the GCL before P6 (Fig. 7D), indicating that

Fig. 6. Cellular identities of cells in the late cohort. Pumps were implanted in pregnant dams at E15.5, and the litters were delivered normally. The pups were sacrificed at P30. Their retinas were labeled retrogradely with rhodamine-dextran and either whole-mounted directly $(\mathrm{A}, \mathrm{B})$ or sectioned and reacted for BrdU with DAPI counterstain (C,D). A: Central retina, including the optic nerve head (*) toward which rhodamine-labeled axons converged. Many of the rhodaminepositive cells are obscured by the bundles of converging fibers. B: Peripheral retina. The ora serrata, the edge of the retina, is at the left. The rhodamine-positive cells are labeled all the way to the edge. C: Peripheral retina. The ora serrata is up. BrdU-positive/rhodaminenegative nuclei (white arrows) mark late cohort displaced amacrines. The BrdU-positive/rhodamine-positive cell (yellow arrow) is a rare late cohort ganglion cell. D: Central retina. The white arrow points to a BrdU-positive/rhodamine-negative cell (a late cohort displaced amacrine cell) flanked by two BrdU-negative/rhodamine-positive cells (non-late cohort ganglion cells. E: The percentages of GCL neurons (mean \pm SEM) are shown for the three cell classes indicated on the horizontal axis. The ganglion cells and displaced amacrines together constituted $100 \%$, of which $20 \%$ were members of the late cohort. F: The percentages of ganglion cells and displaced amacrines (mean \pm $\mathrm{SEM}$ ) in the late cohort. Abbreviations as in Figure 4. Scale bar $=100$ $\mu \mathrm{m}$ in $\mathrm{A}, \mathrm{B} ; 20 \mu \mathrm{m}$ in $\mathrm{C}, \mathrm{D}$. 

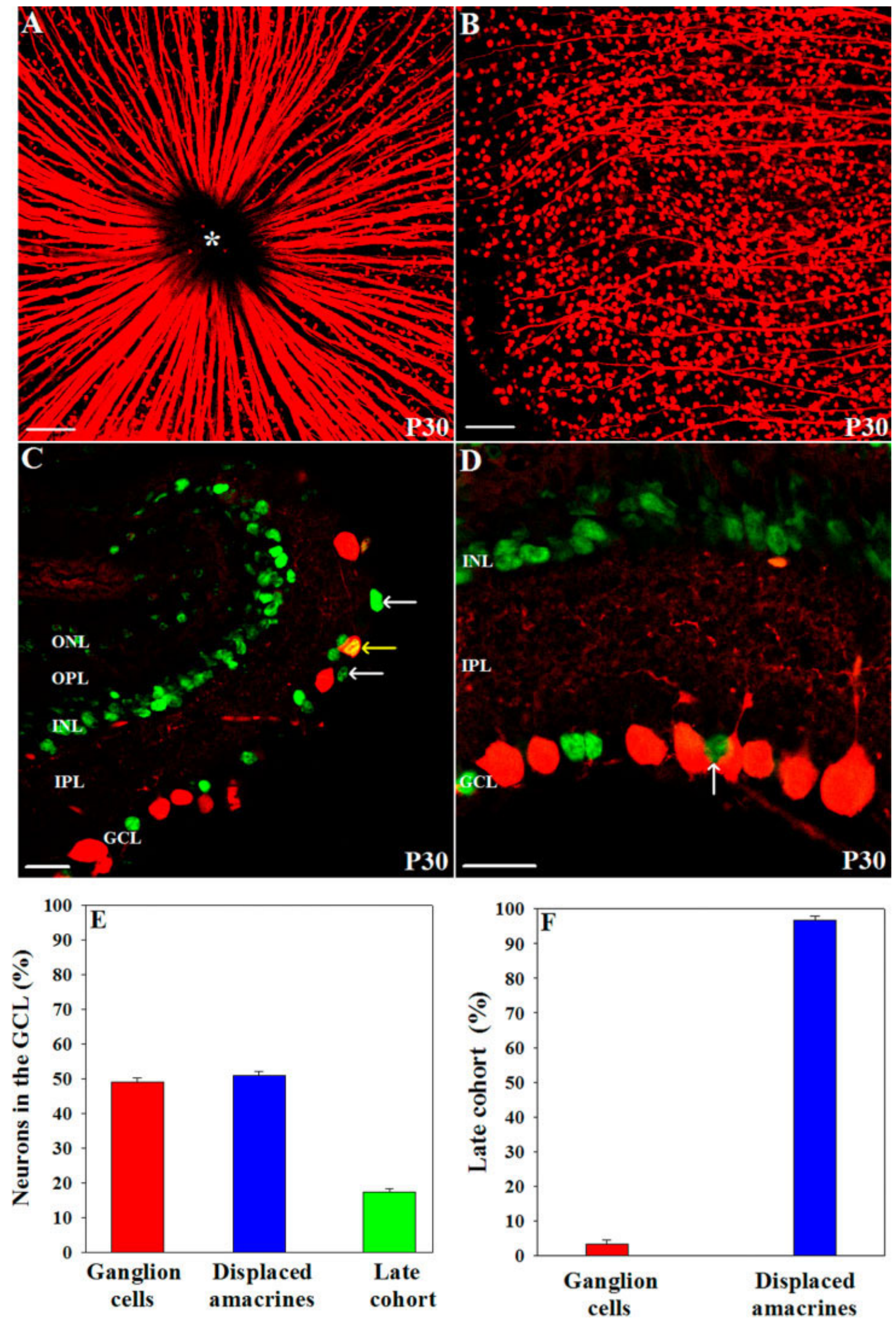

Figure 6 

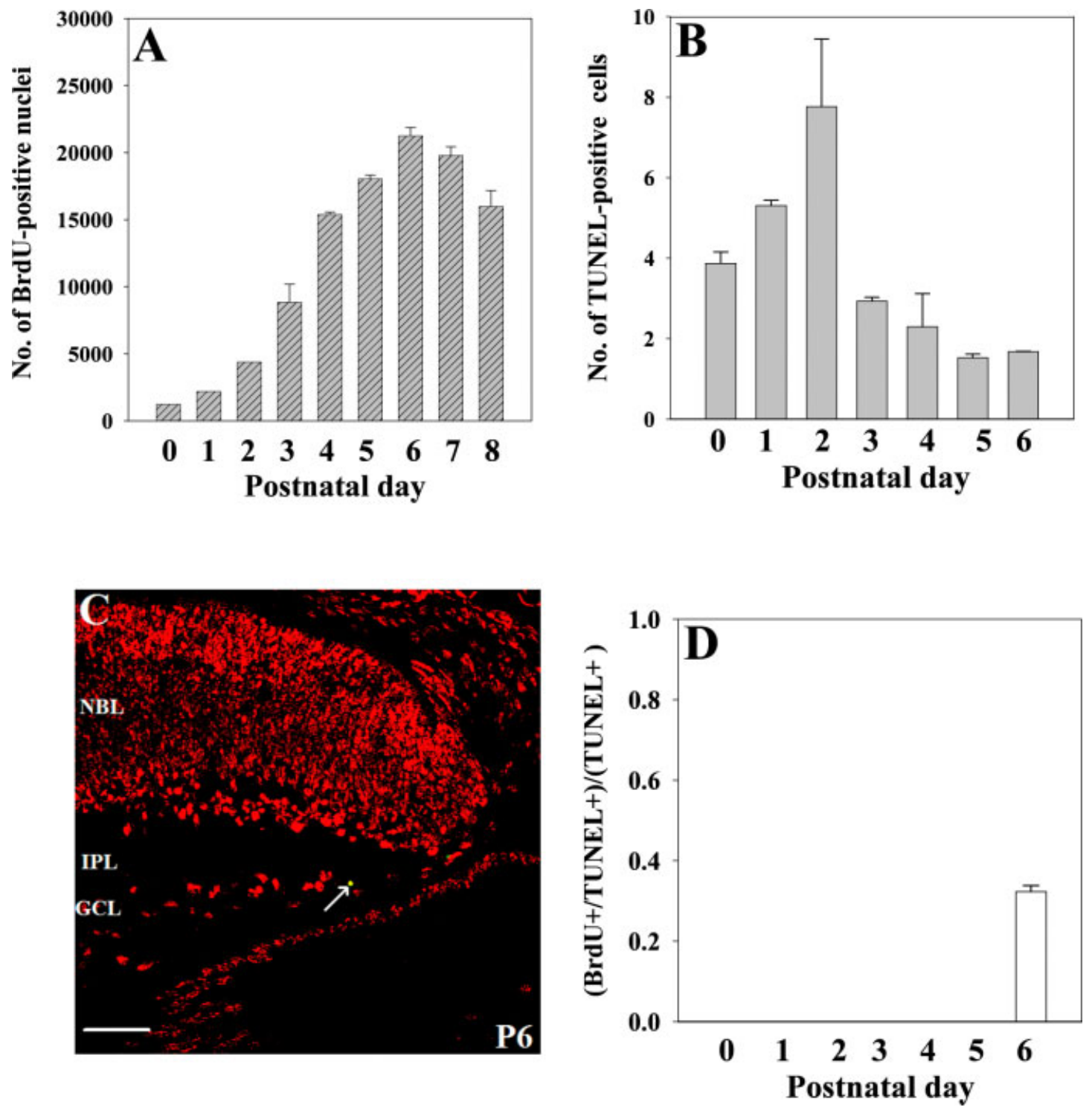

Fig. 7. Postnatal cell death in the late cohort. Pumps were implanted in pregnant dams at E15.5, and the litters were delivered normally. Pups were sacrificed at various ages, and their retinas were sectioned, reacted for BrdU and TUNEL, and counterstained with DAPI. A: The number of BrdU-positive nuclei in the GCL (mean \pm SEM; the late cohort) is plotted vertically against the first 8 postnatal days $(\mathrm{n}=1$ retina at $\mathrm{P} 0-\mathrm{P} 2 ; \mathrm{n}=2$ at $\mathrm{P} 3, \mathrm{P} 7$, and $\mathrm{P} 8$; and $\mathrm{n}=3$ for

cells in the E15.8 cohort did not die before P6. Assuming that no more cells from the late cohort entered the GCL after P6, the number of BrdU-positive neuronal nuclei at P6 was taken as the initial population of the late cohort.

BrdU-positive GCL nuclei with neuronal morphology were counted at $\mathrm{P} 6$ and $\mathrm{P} 30$ ( $\mathrm{n}=14-15$ retinas, $4-5$ litter for each day) and processed with the modified Abercrombie correction to estimate total numbers per retina (Fig. 5B). The numbers of BrdU-positive nuclei were 22,976 \pm 1,756 at $\mathrm{P} 6$ and $16,323 \pm 787$ at P30 $(P<0.05$, Student's $t$-test of the difference between means), a loss of $29.0 \pm$ $12.4 \%$.

P4, P5, and P6). B: The number of TUNEL-positive cells/section in the GCL (mean \pm SEM; $n=2$ retinas at each point). C: Retinal section reacted for TUNEL (green) and BrdU (red). One cell in the GCL was TUNEL-positive/BrdU-positive (arrow). D: The fraction of TUNELpositive/BrdU-positive cells in the GCL (dying members of the late cohort), from the same sections as in B. Abbreviations as in Figures 1 and 4 . Scale bar $=20 \mu \mathrm{m}$ in $\mathrm{C}$.

\section{Relative contributions of the early, intermediate, and late cohorts}

The total number of cells in the GCL was estimated at P0, P6, and P30 to learn what fraction of the total was contributed by cells in the early and late cohorts. Two eyes from two different animals at each age were sectioned and stained with DAPI. The numbers of GCL nuclei with neuronal characteristics were estimated with the modified Abercrombie correction: $121,860 \pm 1,424$ at P0, 120,149 \pm 1,913 at $\mathrm{P} 6$, and $116,316 \pm 8,641$ at P30. All three estimates are quite similar to the values previously published 
for adult mouse retinas (Jeon et al., 1998). The fact that all three numbers are so similar to one another appears surprising in view of our evidence for postnatal cell death, but the similarity is explained by the postnatal migration of new cells into the GCL (Fig. 7A), which nearly balances the loss through cell death.

The contributions of the two cohorts differed in animals of different ages. The numbers of cells produced before E12.8 numbered 9,793 at P0 and 5,044 at P30, or 8.0 and $4.3 \%$, respectively, of the total GCL at those ages. Those cells born after E15.8 numbered 22,976 at P6 and 16,323 at $\mathrm{P} 30$, or 19.1 and $14.0 \%$, respectively, of the totals. Thus these two cohorts contributed about $18.3 \% \quad(=4.3+$ $14.0 \%$ ) of the permanent cells in the GCL, implying that $81.7 \%$ were produced during the intermediate 3 days between E12.8 and E15.8. Young's famous summary diagram of mouse neurogenesis portrays all retinal cell types passing through a similar time course: an initially slow rise that accelerates to a peak followed by a rapid deceleration and a gradual fall. The numbers above confirm that most GCL neurons were produced during the intermediate 3 days and relatively few before and after. A comparison of our two early cohorts reveals the initial acceleration as well. The first cells to withdraw from the mitotic cycle are thought to do so at about E10.5 (Sidman, 1961; Farah, 2004); therefore the E11.8 and E12.8 cohorts revealed the cells that made their terminal S-phases during the first 1 and 2 days, respectively, of GCL neurogenesis. They numbered 3,589 and 9,793, respectively; the difference between the two, 6,204, is the number made during the second day, and it is nearly twice as large as the number made during the first day, direct evidence for the accelerated neurogenesis reported by Young (1985).

In summary, we have shown that ganglion cells and displaced amacrine cells were biased to appear early and late, respectively. Cell death was proportionately greater in the E12.8 cohort than in the E15.8 cohort, but it remains unclear whether this difference is associated with the differences in cell types or birth dates. Most, and possibly all, of the cell death that occurred in the early cohorts was postnatal, long after the end of the period of vulnerability proposed by Galli-Resta and Ensini (1996).

\section{DISCUSSION}

These results bear on two subjects of general interest: the origins of neuronal diversity and developmental cell death.

\section{Generation of neuronal diversity}

Many studies of the vertebrate retina have led to the conclusion that diverse types of neurons are produced sequentially, with GCL neurons first (reviewed in Altshuler et al., 1991). The first evidence came from the classic birth-dating study of Sidman (1961), in which single injections of tritiated thymidine were given at particular ages, and the heavily labeled cells detected much later were inferred to be those that had differentiated "after few further mitoses" following the injection (Table III in Sidman, 1961). Such cells resulted from injections made as early as the 11th day of gestation (in our terminology, between E10.0 and E11.0), implying that terminal S-phases may have occurred as early as that day. Typically, most of the earliest cells so identified were in the GCL, and injections at later ages produced heavily labeled cells in other layers (Sidman, 1961; Lavail et al., 1991; Rapaport et al., 2004). This sequential production resulted from multipotent progenitors that divided asymmetrically to produce different cell types at different times (Turner and Cepko, 1987; Wetts and Fraser, 1988; Holt et al., 1988; Turner et al., 1990). The type of cell produced at any time is believed to depend on both internal and external factors (Cepko et al., 1996; Harris, 1997; Livesey and Cepko, 2001; Marquardt and Gruss, 2002). A progenitor cell's "competence" to respond to a particular external signal dictates what type of cell it will produce, and the competence changes over time.

This model deals with individual progenitor cells, and we attempt to extend it to the population of progenitors by addressing the question of whether they are homogeneous or heterogeneous. This question can be answered by learning whether the population produces one or more cell types; one type of progeny implies that the progenitors were homogeneous (uniformly competent), and more than one implies that they were heterogeneous. The strongest evidence for uniform competence came from zebrafish retina, in which the initial period of terminal mitoses (about 8 hours long) resulted in exclusively GCL neurons, and subsequent intervals made inner and then outer nuclear layer neurons ( $\mathrm{Hu}$ and Easter, 1999). In zebrafish that were mutant in the atonal homolog, ath5/lakritz, the initial burst of terminal divisions failed to occur and no ganglion cells appeared, but outer retinal cells were produced on schedule (Kay et al., 2001). The GCL in zebrafish is nearly exclusively ganglion cells (S. S. Easter, Jr., unpublished data); therefore the progenitors were overwhelmingly ganglion cell-competent during the first neurogenic burst.

Other work, in amniotes, argued against homogeneity. Sidman (1961) included ganglion, amacrine, and horizontal cells among those that were produced on the first day of mouse retinogenesis, and Carter-Dawson and Lavail (1979) added cones to this trio. (Young [(1985] claimed further that cones and amacrines were produced in greater numbers than GCL neurons at this early time, but that will be disputed below.) Harman and Beazley (1989) and Reese and Colello (1992), studying the quokka and rat, respectively, addressed the narrower question of whether ganglion and displaced amacrine cells were produced simultaneously, and they concluded that they were. Belecky-Adams et al. (1996) examined chick retina relatively late in development, using "window-labeling," a temporally precise method of birth dating, to show that many dissimilar neuronal types were born nearby one another during the same brief window of time. These results in situ were supplemented by studies in vitro of dissociated retinal progenitors that simultaneously produced a wide variety of cell types (e.g., 26\% amacrines, $25 \%$ cones, $20 \%$ rods, and smaller amounts of others: Belliveau and Cepko, 1999).

Is the zebrafish neurogenetic program simply different from that of amniotes, as Livesey and Cepko (2001) have suggested, or can these disparate results be reconciled? We argue that they can be reconciled and that the apparent differences are associated with the stage of retinal development. Our E15.8 cohort, restricted as it was to the cells ending up in the GCL, was a small fraction of all the cells born after E15.8, most of which were destined for the inner and outer nuclear layers. Therefore the competences were varied in the population of progenitors after E15.8, 
consistent with all the papers cited above. Late in neurogenesis, the competences of precursors are diverse. However, conditions were different before E12.8, when the bias toward ganglion cells was much stronger. The vast majority of neurons produced before that age settled in the GCL (Fig. 1B), and 98-99\% of those that did were ganglion cells. This conclusion is qualitatively consistent with some descriptions of early neurogenesis (Sidman, 1961; CarterDawson and Lavail, 1979) but quantitatively inconsistent with the claim that both cones and amacrine cells are produced in greater numbers than GCL neurons (Young, 1985).

We believe that Young's conclusion was unjustified; Young studied postnatal neurogenesis exclusively, and did so quantitatively. He combined the qualitative data of Sidman (1961) and Carter-Dawson and Lavail (1979) in an unspecified manner with his quantitative data to produce a summary graph (his Fig. 9). Because it purports to describe quantitatively the entire process of retinogenesis, it has been widely reproduced, but the prenatal portion is speculative and inconsistent with our direct demonstration that early neurons are overwhelmingly ganglion cells. Then what of Harman and Beazley (1989) and Reese and Colello (1992), who found that ganglion and displaced amacrines were born simultaneously from the beginning? The earliest age that Harman and Beazley (1989) examined was P1, but ganglion cells first appear about 5 days prior to birth in the quokka (Harman and Beazley, 1987); therefore this study missed what we believe to be the crucial first days. Reese and Colello (1992) used pulse labeling at daily intervals to reveal the percentage of displaced amacrine cells in the GCL on a daily basis and showed that it rose from E14, the first day that injections produced heavily labeled cells, to E20. This is qualitatively the same as our conclusion but quantitatively a bit different. Their starting value, at E14, was about $13 \%$, considerably higher than our starting values of $1-2 \%$ and was anomalously higher than their value at E15 (about $6 \%$ ). We favor their suggestion that this initial point may be suspect.

We believe that our cumulative label is better suited to establishing a boundary for birth dates than the pulseinjection/heavy label paradigm. Sidman, who invented the latter paradigm, carefully defined heavily labeled cells as having differentiated "after few further mitoses" following injection. Assuming that the length of the cell cycle is a significant fraction of a day (Alexiades and Cepko, 1996), then "a few further mitoses" would need a day or more to be completed, implying a substantial uncertainty about when a heavily labeled cell made its terminal S-phase. Sidman's qualitative assessment of heavy label has been quantified by counting silver grains; the nuclei with the most silver grains are those that have experienced the fewest mitoses between the time of the injection and the exit from the cell cycle. They are the earliest born, but their birth dates remain uncertain because the "standard" grain density cannot be tied securely to a particular birth date. This uncertainty proved troublesome in the recent paper by Rapaport et al. (2004) in which test sections from particular experiments were developed every week until the maximum label reached a criterion grain density, at which time all the sections in that batch were developed. This method allows longer photographic development to compensate for less tritium in the nuclei. If the smaller amount of tritium resulted from dilution through mitosis, then the estimated birth dates of the heavily labeled cells would be spuriously early in those sections that had experienced longer development. Indeed, Rapaport et al. (2004) reported birth dates of GCL cells as early as E10, 4 days earlier than the previous estimate by Reese and Colello (1992), who developed all sections equally. Rapaport et al. (2004) acknowledged some of the shortcomings of the pulse-injection/heavy label paradigm and concluded that cumulative labeling is preferable for determining the onset of terminal mitoses, as it provides an unambiguous criterion, labeled vs. unlabeled, that divides those cells born after implantation from those born before. We agree, and conclude that the earliest progenitors were nearly homogeneous with respect to competence. A very small fraction of terminal mitoses produced cells that were not destined for the GCL, and of those that did end up there, 98-99\% were ganglion cells.

Note that most proliferative cells did not produce neurons during the early period, but the subpopulation that did produce them was nearly uniform. The competences of the others, those that divided symmetrically, are uncertain. They may have been ganglion cell-competent but were prevented from entering that pathway by the actions of Notch (Austin et al., 1995). Alternatively, they may have been competent to produce other cell types but failed to do so because of a lack of the appropriate external signal.

Another possible mechanism contributing to neuronal diversity is a postmitotic shift in cell fate. In their electron microscopic study of embryonic mouse retina, Hinds and Hinds (1978) saw degenerating axons in the optic fiber layer. They proposed that some of the early neurons initially had axons (i.e., they were ganglion cells) and later shed them to became amacrine cells. We found that about $99 \%$ of the early cohort were ganglion cells even at P30; therefore very few cells, if any, could have changed fate.

\section{Developmental cell death}

Our method for determining cell death is straightforward: count the number in a cohort at both early and late dates and subtract. This avoids the pitfalls of earlier studies that were based on uncertain assumptions, such as the clearance time of dying cells, and the contribution of new cells born after death had begun in the population. We concluded that about half of the ganglion cells of the early cohort died, which is in line with most of the other estimates (Rager and Rager, 1978; Hughes and Mcloon, 1979; Sengelaub and Finley, 1982; Perry et al., 1983; Rakić and Riley, 1983; Sefton and Lam, 1984; Crespo et al., 1985; Lia et al., 1986; Williams et al., 1986; Voyvodic et al., 1995), save three, each of which warrants some discussion.

The first is that of Young (1984), who estimated that only $9 \%$ died. That low estimate was viewed skeptically by the author, who noted that it assumed a clearance time for dying cells of 24 hours. It is now known to be much too long (Harvey and Robertson, 1992; Voyvodic et al., 1995).

The second outlier is from Strom and Williams (1998). They examined 10 strains of mice (not including CD-1) and compared axon counts in the optic nerves at P0 and after retinal cell death. They found relatively uniform percentage loss, averaging about $69 \%$ compared with our result of $48.5 \%$. The explanation for this difference may lie in the different methods, or the different strains, or birth date-specific differences in mortality. 
The third outlier came from Galli-Resta and Ensini (1996), who concluded that cells died only during the first 5 days after they were born (they were subject to the "cell death clock"), which complicates greatly the estimate of total cell death. They attempted to correct for the simultaneity of death and birth and estimated that $90 \%$ of the ganglion cells died. To evaluate the $90 \%$ estimate, we restricted our analysis to the early cohort, which we showed had no cell death prior to the implantation of the pump, and found that $48.5 \%$ of the ganglion cells died, not $90 \%$. To evaluate the claim of a brief early period of vulnerability (the "cell death clock"), we counted cells in the early cohort soon after it was produced and 7 days later, at E18.5. If cells were vulnerable to death only during the first few days, then the second number should have been considerably smaller than the first. Instead, the difference between the two was statistically insignificant. This was consistent with an earlier TUNEL staining of embryonic retina, which showed scarcely any TUNEL-positive GCL cells (Farah, 2004). The E15.8 cohort produced similar results; TUNEL-positive cells of the E15.8 cohort were absent until P6, about 8 days after the birthdays of the earliest born members of this cohort (Fig. 7). These results indicate the opposite of an initial period of vulnerability; instead, the cells experience an initial grace period, a few days of invulnerability. This conclusion is further supported by the earlier onset of TUNEL-positive cells born earlier than the late cohort. TUNEL-positive cells were found in the GCL during P0-P5, but all of these were BrdU-negative and had therefore been born before E15.8. The GCL contained plenty of E15.8 cohort cells during P0-P5, but none were TUNEL-positive (Fig. 7). Therefore the older cells died before the younger ones, consistent with the idea that their grace period had expired before that of cells born later. Gould et al. (1999), in their study of chick spinal motor neurons, had also concluded that older cells died before younger ones. In summary, our results show that cells are spared for a few days following their birthday. Rather than face cellular infanticide, they get a free pass during their youth, and naturally occurring death, if it is to come, arrives later.

\section{ACKNOWLEDGMENTS}

We thank Professor Connie Cepko for her useful comments on the article. This work was completed in partial fulfillment of the Ph.D. degree for M.H.F.

\section{LITERATURE CITED}

Abercrombie M. 1946. Estimation of nuclear population from microtome sections. Anat Rec 94:239-247.

Alexiades MR, Cepko CL. 1996. Quantitative analysis of proliferation and cell cycle length during development of the rat retina. Dev Dyn 205 : 293-307.

Alexiades MR, Cepko CL. 1997. Subsets of retinal progenitors display temporally regulated and distinct biases in the fates of their progeny. Development 124:1119-1131.

Altshuler D, Turner DL, Cepko CL. 1991. Specification of cell type in the vertebrate retina. In: Lam DM-K, Shatz CJ, editors. Development of the visual system. Cambridge: MIT Press. p 37-58.

Armstrong RC, Clarke PG. 1979. Neuronal death and the development of the pontine nuclei and inferior olive in the chick. Neuroscience 4:16351647.

Austin CP, Feldman DE, Ida JA, Cepko CL. 1995. Vertebrate retinal ganglion cells are selected from competent progenitors by the action of Notch. Development 121:3637-3650.
Belecky-Adams T, Cook B, Adler R. 1996. Correlations between terminal mitosis and differentiated fate of retinal precursor cells in vivo and in vitro: analysis with the "window-labeling" technique. Dev Biol 178: $304-315$.

Belliveau MJ, Cepko CL. 1999. Extrinsic and intrinsic factors control the genesis of amacrine and cone cells in the rat retina. Development 126:555-565.

Carter-Dawson LD, LaVail MM. 1979. Rods and cones in the mouse retina. II. Autoradiographic analysis of cell generation using tritiated thymidine. J Comp Neurol 188:263-272.

Cepko CL, Austin CP, Yang X, Ezzeddine D. 1996. Cell fate determination in the vertebrate retina. Proc Natl Acad Sci U S A 93:589-595

Cook B, Portera-Cailliau C, Adler R. 1998. Developmental neuronal death is not a universal phenomenon among cell types in the chick embryo retina. J Comp Neurol 396:12-19.

Crespo D, O'Leary DDM, Cowan WM. 1985. Changes in the numbers of optic nerve fibers during late prenatal and postnatal development in the albino rat. Dev Brain Res 1:129-134.

Dräger UC. 1985. Birth dates of retinal ganglion cells giving rise to the crossed and uncrossed optic projections in the mouse. Proc R Soc Lond B Biol Sci 224:57-77.

Dräger UC, Olsen JF. 1981. Ganglion cell distribution in the retina of the mouse. Invest Ophthalmol Vis Sci 20:285-293.

Easter SS Jr, Ross LS, Frankfurter A. 1993. Initial tract formation in the mouse brain. J Neurosci 13:285-299.

Farah MH. 2004. Cumulative labeling of embryonic mouse neural retina with bromodeoxyuridine supplied by an osmotic minipump. J Neurosci Methods 134:169-178.

Frank E, Harris WA, Kennedy MB. 1980. Lysophosphatidyl choline facilitates labeling of CNS projections with horseradish peroxidase. J Neurosci Methods 2:183-189.

Fritzsch B. 1993. Fast axonal diffusion of 3000 molecular weight dextran amines. J Neurosci Methods 50:95-103.

Galli-Resta L, Ensini M. 1996. An intrinsic time limit between genesis and death of individual neurons in the developing retinal ganglion cell layer. J Neurosci 16:2318-2324.

Gould TW, Burek MJ, Sosnowski JM, Prevette D, Oppenheim RW. 1999. The spatial-temporal gradient of naturally occurring motoneuron death reflects the time of prior exit from the cell cycle and position within the lateral motor column. Dev Biol 216:611-621.

Harman AM, Beazley LD. 1987. Patterns of cytogenesis in the developing retina of the wallaby Setonix brachyurus. Anat Embryol 177:123-130.

Harman AM, Beazley LD. 1989. Generation of retinal cells in the wallaby, Setonix brachyurus (quokka). Neuroscience 28:219-232.

Harris WA. 1997. Cellular diversification in the vertebrate retina. Curr Opin Gen Dev 7:651-658.

Harvey AR, Robertson D. 1992. Time course and extent of retinal ganglion cell death following ablation of the superior colliculus in neonatal rats. J Comp Neurol 325:83-94.

Hayden SA, Mills JW, Masland RM. 1980. Acetylcholine synthesis by displaced amacrine cells. Science. 210:435-437.

Hinds JW, Hinds PL. 1978. Early development of amacrine cells in the mouse retina: an electron microscopic, serial section analysis. J Comp Neurol 179:277-300

Hollyfield JG. 1972. Histogenesis of the retina in the killifish, Fundulus heteroclitus. J Comp Neurol 144:373-380.

Holt CE, Bertsch TW, Ellis HM, Harris WA. 1988. Cellular determination in the Xenopus retina is independent of lineage and birth date. Neuron $1: 15-26$.

Hu M, Easter SS Jr. 1999. Retinal neurogenesis: the formation of the initial central patch of postmitotic cells. Dev Biol 20:309-321.

Hughes WF, McLoon SC. 1979. Ganglion cell death during normal retinal development in the chick: comparisons with cell death induced by early target field destruction. Exp Neurol 66:587-601.

Jacobson M. 1991. Developmental neurobiology. New York: Plenum.

Jeon CJ, Strettoi E, Masland RH. 1998. The major cell populations of the mouse retina. J Neurosci 18:8936-8946.

Kay JN, Finger-Baier KC, Roeser T, Staub W, Baier H. 2001. Retinal ganglion cell genesis requires lakritz, a zebrafish atonal homolog. Neuron 30:725-736.

Konigsmark BW. 1970. Methods for the counting of neurons. In: Nauta WJH, Ebbesson SOE, editors. Contemporary research methods in neuroanatomy. Heidelberg: Springer-Verlag. p 315-338. 
LaVail MM, Rapaport DH, Rakic P. 1991. Cytogenesis in the monkey retina. J Comp Neurol 309:86-114.

Lee EJ, Kim IB, Lee E, Kwon SO, Oh SJ, Chun MH. 2003. Differential expression and cellular localization of doublecortin in the developing rat retina. Eur J Neurosci 17:1542-1548.

Lia B, Williams RW, Chalupa LM. 1986. Does axonal branching contribute to the overproduction of optic nerve fibers during early development of the cat's visual system? Brain Res 390:296-301.

Livesey FJ, Cepko CL. 2001. Vertebrate neural cell-fate determination: lessons from the retina. Nat Rev Neurosci 2:109-118.

Marquardt T, Gruss P. 2002. Generating neuronal diversity in the retina: one for nearly all. Trends Neurosci 25:32-38.

Marquardt T, Ashery-Padan R, Andrejewski N, Scardigli R, Guillemot F, Gruss P. 2001. Pax6 is required for the multipotent state of retinal progenitor cells. Cell 105:43-55.

McKay SE, Oppenheim RW. 1991. Lack of evidence for cell death among avian spinal cord interneurons during normal development and following removal of targets and afferents. J Neurobiol 22:721-733.

Perry VH, Henderson Z, Linden R. 1983. Postnatal changes in retinal ganglion cell and optic axon populations in the pigmented rat. J Comp Neurol 219:356-368.

Rachel RA, Dolen G, Hayes NL, Lu A, Erskine L, Nowakowski RS, Mason CA. 2002. Spatiotemporal features of early neuronogenesis differ in wild-type and albino mouse retina. J Neurosci 22:4249-4263.

Rager G, Rager U. 1978. Generation and degeneration of retinal ganglion cells in the chicken. Exp Brain Res 25:551-553.

Rakic P, Riley KP. 1983. Overproduction and elimination of retinal axons in the fetal rhesus monkey. Science 219:1441-1444.

Rapaport DH, Wong LL, Wood ED, Yasumura D, LaVail MM. 2004. Timing and topography of cell genesis in the rat retina. J Comp Neurol 474: $304-324$.

Reese BE, Colello RJ. 1992. Neurogenesis in the retinal ganglion cell layer of the rat. Neuroscience 46:419-429.

Rich KA, Zhan Y, Blanks JC. 1997. Migration and synaptogenesis of cone photoreceptors in the developing mouse retina. J Comp Neurol 388:4763.
Schnitzer J, Rusoff AC. 1984. Horizontal cells of the mouse retina contain glutamic acid decarboxylase-like immunoreactivity during early developmental stages. J Neurosci 4:2948-2955.

Sefton AJ, Lam K. 1984.. Quantitative and morphological studies on developing optic axons in normal and enucleated albino rats. Exp Brain Res 57:107-117

Sengelaub DR, Finlay, BL. 1982. Cell death in the mammalian visual system during normal development: I. Retinal ganglion cells. J Comp Neurol 204:311-317.

Sidman RL. 1961. Histogenesis of mouse retina studied with thymidine$\mathrm{H}^{3}$. In: Smelser G, editor. Structure of the eye. New York: Academic Press. pp 487-506.

Straznicky K, Gaze RM. 1971. The growth of the retina in Xenopus laevis: an autoradiographic study. J Embryol Exp Morphol 26:67-79.

Strom RC, Williams RW. 1998. Cell production and cell death in the generation of variation in neuron number. J Neurosci 18:9948-9953.

Turner DL, Cepko CL. 1987. A common progenitor for neurons and glia persists in rat retina late in development. Nature 328:131-136.

Turner DL, Snyder EY, Cepko CL. 1990. Lineage-independent determination of cell type in the embryonic mouse retina. Neuron 4:833-845.

Von Bohlen und Halbach O. 1999. The isolated mammalian brain: an in vivo preparation suitable for pathway tracing. Eur $J$ Neurosci 11: 1096-1100.

Voyvodic JT, Burne JF, Raff MC. 1995. Quantification of normal cell death in the rat retina: implications for clone composition in cell lineage analysis. Eur J Neurosci 7:2469-2478.

Wetts R, Fraser SE. 1988. Multipotent precursors can give rise to all major cell types of the frog retina. Science 239:1142-1145.

Williams RW, Bastiani MJ, Lia B, Chalupa LM. 1986. Growth cones, dying axons, and developmental fluctuations in the fiber population of the cat's optic nerve. J Comp Neurol 246:32-69.

Young RW. 1984. Cell death during differentiation of the retina in the mouse. J Comp Neurol 229:362-373.

Young RW. 1985. Cell differentiation in the retina of the mouse. Anat Rec 212:199-205. 